imperative if the work of the hospital was to be efficiently carried on.

The out-patient department in the new building was opened on April 10 last, and it is hoped that the remainder of the hospital will be completed within a few weeks. An important feature of the new hospital is the provision of a number of rooms for paying patients, in order to meet the needs of those who cannot afford the cost of treatment in private nursing homes.

\title{
The Oculist
}

In the Trans. Ophthal. Soc. U.K., 1921, p. 342, will be found an account of Sir William Read, Oculist to Queen Anne. A tract in the British Museum, with the above title was alluded to as a fulsome eulogy. We recently secured a copy of the tract in question and give some extracts here for the amusement of our readers.

The tract is a small quarto, published in 1705 ; it is anonymous, and consists of five pages of introduction and 113 lines of poetry. Sufficient extracts from the introduction are given in the paper in question; here we propose to take a few couplets from the poem.

"The OCUILIST moves in an Orb more bright :-

The EYE's his Province; that bright Optick Sphere, By which we move, and act, and guide, and steer.-

No Price too high the darling EYES to save,

When .Life without 'em's but a walking Grave.--

And if bold Esculapius cou'd aspire

So high, to claim Apollo for his Sire,

The OCULIST, with his more shining WORTH, Is sure the radiant Phoebus Eldest Birth :-

READ is the leading CONQUEROR in this Field.-

Your ministring Art and unbought Labours given

For no Return, unless repay'd by Heav'n.

So frankly good, and so profusely kind,

Has Your long Charitable Glory shin'd;

So bred in tender Pity's generous School,

Kind as the Angel at Bethesda's Pool."-

Enough extracts have been given from this poem; it would have been interesting to have known who was the author of these lines. They should be compared with the lines by the Chevalier Taylor's grandson, quoted by Coats in the last volume of the Moorfields Hospital Reports. To the best of our recollection they deal with 
an unsatisfactory result of a cataract operation performed by a qualified surgeon, and end up :

"Hence nothing I could say should smart 'em,

The eye was lost secundum artem."

Most of us have lost an eye or two, secundum artem, in our time; but we would rather not break out into verse about it.

The tract in question has been presented to the Bowman Library.

\section{COUNCIL OF BRITISH OPHTHALMOLOGISTS}

\section{Annual Report}

THE Council presents its report for the Session 1927-28. At the first meeting the following were elected as officers :-President : Mr. J. Herbert Fisher; Vice-Presidents : Sir George Berry, M.P. and Sir John Parsons; Hon. Treasurer : Mr. M. S. Mayou; Hon. Secretary : Mr. Frank Juler.

The following were appointed to serve on the Executive Committee : The President and Hon. Secretary (ex officiis), with Mr. E. Treacher Collins, Sir John Parsons, Mr. M. S. Mayou and Mr. W.H. McMullen.

\section{The Optical Practitioners (Registration) Bill, 1927}

Continuing its action in opposition to this Bill, to which the Council referred in its last annual report, a special committee prepared a statement of evidence. The Council, having approved this draft, nominated the President with Messrs. Adams, Gray Clegg, Mayou, Walker and Whitehead to attend and give evidence before the Departmental Committee appointed by the Minister of Health. The report of the Departmental Committee has since been published. (H.M. Stationery Office, Cmd. 2999.)

\section{Medical Certificates of Blindness}

The Council was approached as to the remuneration available for medical men supplying certificates of blindness in the case of persons applying at voluntary hospitals. The Council obtained from the Ministry of Health a statement which has been published in the British Journal of Ophthalmology (Feb., 1928, pp.96-98). This statement enumerates clearly the several bodies by which such certificates are required, and shows for what certificates funds should be available. 